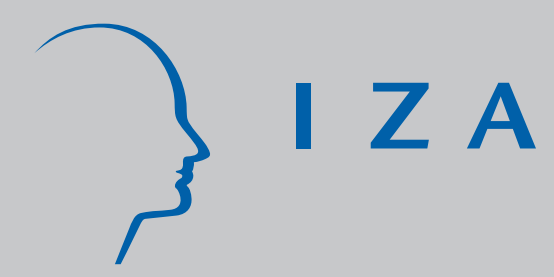

IZA DP No. 473

A pint a day raises a man's pay; but smoking blows that gain away

J an C. van Ours

April 2002 


\title{
A pint a day raises a man's pay; but smoking blows that gain away
}

\author{
Jan C. van Ours \\ CentER for Economic Research, Tilburg University, OSA, \\ CEPR and IZA, Bonn
}

\author{
Discussion Paper No. 473 \\ April 2002
}

\author{
IZA \\ P.O. Box 7240 \\ D-53072 Bonn \\ Germany \\ Tel.: +49-228-3894-0 \\ Fax: +49-228-3894-210 \\ Email: iza@iza.org
}

This Discussion Paper is issued within the framework of IZA's research area The Future of Labor. Any opinions expressed here are those of the author(s) and not those of the institute. Research disseminated by IZA may include views on policy, but the institute itself takes no institutional policy positions.

The Institute for the Study of Labor (IZA) in Bonn is a local and virtual international research center and a place of communication between science, politics and business. IZA is an independent, nonprofit limited liability company (Gesellschaft mit beschränkter Haftung) supported by the Deutsche Post AG. The center is associated with the University of Bonn and offers a stimulating research environment through its research networks, research support, and visitors and doctoral programs. IZA engages in (i) original and internationally competitive research in all fields of labor economics, (ii) development of policy concepts, and (iii) dissemination of research results and concepts to the interested public. The current research program deals with (1) mobility and flexibility of labor, (2) internationalization of labor markets, (3) welfare state and labor markets, (4) labor markets in transition countries, (5) the future of labor, (6) evaluation of labor market policies and projects and (7) general labor economics.

IZA Discussion Papers often represent preliminary work and are circulated to encourage discussion. Citation of such a paper should account for its provisional character. A revised version may be available on the IZA website (www.iza.org) or directly from the author. 
IZA Discussion Paper No. 473

April 2002

\section{ABSTRACT \\ A pint a day raises a man's pay; but smoking blows that gain away*}

This paper studies the wage effects of the use of alcohol and tobacco. The analysis based on a recent survey in the Netherlands shows that for males the use of tobacco has a negative wage effect of about $10 \%$ while the use of alcohol has a positive wage effect of about the same size. The wages of females are not affected by smoking and drinking.

JEL Classification: C41, D12, I19

Keywords: drinking, smoking, wages, earnings regressions

Jan C. van Ours

Department of Economics and CentER

Tilburg University

P.O. Box 90153

5000 LE Tilburg

The Netherlands

Tel.: +31-13-4662316

Fax: +31-13-4663042

Email: vanours@kub.nl

\footnotetext{
* The author thanks CentER-data for making their data available and CentER for financial support in the data collection. Furthermore, he thanks seminar participants at IZA for stimulating comments.
} 


\section{Introduction}

There is a small literature on the relationship between drinking, smoking and labor market performance. Most of the studies in this literature focus on the exect of alcohol on wages, some studies are on the infuence of smoking on wages and there are also a few studies on the simultaneous exect of smoking and drinking on wages. ${ }^{1}$

The studies based on US, Canadian or A ustralian data all ..nd positive wage exects of moderate alcohol use. ${ }^{2}$ The positive wage exects of drinking are explained through the relationship between drinking and health. Moderate drinkers have a smaller probability to be confronted with coronary heart disease than abstainers or heavy drinkers have. The exact nature of the relationship between alcohol use and wages dixers. Basically, there are two types of results. Drinking has a positive but constant wage exect over some range of use. Or there is an inverted $\mathrm{U}$-shape relationship where there is a maximum positive wage exect at some drinking intensity while drinking more or drinking less induces a smaller wage exect. Examples of the ..rst type of studies are Berger and Leigh (1988) and Zarkin et al. (1998). Berger and Leigh (1988) ...nd that drinkers receive higher wages than non-drinkers. Zarkin et al. (1998) conclude that men who use alcohol over a wide range of consumption levels have $7 \%$ higher wages than men who do not drink or are heavy drinkers. The study does not ..nd a statistically signi...cant alcohol wage premium for females. Examples of the second type of studies are French and Zarkin (1995), Heien (1996), Hamilton and Hamilton (1997) and M acD onald and Shields (2001). French and Zarkin (1995) ...nd that individuals who consume 1.5 to 2.5 alcoholic drinks per day have significantly higher wages than abstainers and heavy drinkers. Heien (1996) ..nds that at the optimal level of alcohol consumption the wage premium of alcohol is around 50\%. Hamilton and Hamilton (1997) ..nd a non-linear exect of alcohol use on wages but only after accounting for endogeneity in the choice of drinking status. MacDonald and Shields (2001) study the exect of alcohol consumption on occupational attainment in England. They ..nd both for OLS and 2SLS estimates that there is a positive association between alcohol consumption and mean occupational wages that appears to have an inverted-U shape form. The 2SLS estimates indicate an optimal alcohol consumption equivalent to about 2 pints of beer a day for males and about 1.5 per day for females.

\footnotetext{
${ }^{1}$ There is also research on the use of soft and hard drugs in relation to labor supply. See for an overview of the literature on drugs and labor market performance MacD onald and Pudney (2000).

${ }^{2} \mathrm{An}$ exception is Dave and Kaestner (2002) who claim that alcohol use does not adversely axect labor market outcomes.
} 
The study by Levine et al. (1997) is a rare exception of a study that investigates the exect of smoking on wages. They ..nd that conditional on their observed characteristics workers who smoke earn 4-8\% less than nonsmokers. From a theoretical point of view this negative exect of smoking on wages can be attributed to discrimination of smokers, their reduced ability to carry out manual tasks, their increased absenteeism or their high rate of time preference, which induces them to make fewer investments in productivity enhancing human capital. The results are partly based on panel estimates focusing on dixerences in wages changes between workers that quit smoking and workers that continue smoking. Unfortunately, the investigation on the possible nature of the negative wage exect is without results.

Studies that investigate the simultaneous exects of smoking and drinking on wages are Auld (1998) and Lye and Hirschberg (2001). Auld (1998) ..nds that abstention from alcohol incurs a wage loss of $10 \%$ while being a daily smoker is associated with a wage loss of $8 \%$. After accounting for simultaneity he ..nds that drinking abstention and heavy drinking are associated with an income penalty of $25 \%$ to $50 \%$, whereas a daily smoker has a wage of about $30 \%$ lower than a non-smoker. Lye and Hirschberg (2001) ..nd a non-linear relationship between alcohol use and wages but only for non-smokers. For smokers no positive wage exect of the use of alcohol is found.

The focus of the current paper is on the simultaneous wage exects of the use of alcohol and tobacco. The analysis uses data from a 2001 survey in the Netherlands. From OLS wage regressions it appears that for males drinking has a wage premium of $13 \%$ while smoking has a wage penalty of $6 \%$. The positive wage exect of drinking could be related to better job performance, while smoking is related to worse job performance. However, it could also be that there are unobserved characteristics that axect both smoking/ drinking behavior and wages in which case OLS-estimates are biased. The main issue of the current paper is to estimate the exects of smoking and drinking on wages taking into account the exects of possible unobserved heterogeneity. A traditional way is to use instrumental variables where frequently used instruments are religion, prices of alcoholic beverages, diseases, self-assessment or family behavior. $^{3}$ In 2SLS and 3SLS estimates I use as instrumental variables whether or not an individual started drinking or smoking before age 16. Then I ..nd that the positive exect of drinking increases to implausibly

\footnotetext{
${ }^{3} \mathrm{M}$ acD onald and Shields (2001) for example use instrumental variables related to illnesses of the interviewee (diabetes, stomach ulcers and asthma), the parents of the interviewee (whether or not they smoked regularly) and self-assessment about the drinking behavior of the interviewee.
} 
high values. Such increases in the exect of drinking when applying 2SLS or 3SLS are also found in studies by Zarkin et al. (1998), Heien (1996) and Auld (1998). The size of the exects of alcohol use are very implausible. A pparently it is not easy to ...nd good instrumental variables that axect the choice to drink alcohol but do not directly axect the wage. Therefore, as an alternative to the usual instrumental variable approach I use the analysis of starting rates for alcohol and tobacco to identify the presence of unobserved heterogeneity and relate this to unobserved heterogeneity in the wage equation. My alternative estimates show that alcohol use generates a wage premium for males of about $10 \%$ while smoking reduces wages by about $10 \%$. For females I do not ..nd that drinking or smoking axect wages.

The paper is set up as follows. Section 2 gives stylized facts about the labor market position and smoking and drinking of the individuals in the dataset. Section 3 presents parameter estimates of the starting rates for alcohol and tobacco and parameter estimates of the intensity of use of tobacco and alcohol. Section 4 gives the results of several wage regressions in which the use of tobacco and the use of alcohol are explanatory variables. Section 5 concludes.

\section{Labor market position, smoking and drinking}

The data used in the analysis are collected just before Christmas 2001 (see the Appendix for details about the data). The gross dataset contains information on 1010 males and 820 females aged 16 years and older. Table 1 shows the labor market position of these individuals distinguished by age and gender. Only a few individuals are unemployed. For males the share of unemployed ranges from 1 to $3 \%$, for females this is somewhat higher ranging from 3 to $7 \%$. Only for the lowest age category and the highest age category males and females are very much alike. For both males and females the age category 16 to 25 years contains a little over $50 \%$ of employed workers, while a bit more than $40 \%$ is non-participant. These are mainly individuals that have full time education. For the highest age category almost all individuals are nonparticipants. In the age groups 26 to 35 years and 36-45 years almost all males are employed. In the category 46-55 years there are more nonparticipants, mainly because some of the males retire early or collect disability bene.ts. In the age category 56 to 65 years only $40 \%$ of the males is employed, while $60 \%$ is non-participant, early retired worker or a worker collecting disability bene.ts. For females the age category 26 to 35 years has the highest employment share, $86 \%$, while $10 \%$ of this age category is non-participant. At higher ages the employment share drops substantially to $17 \%$ for the age category 56 to 65 years. 
Table 2 shows the use of tobacco and alcohol by age group and gender. The indicators shown are lifetime prevalence, last year prevalence and last month prevalence. In most studies it is not possible to study past use independently of current use because last month prevalence automatically implies lifetime prevalence. Here these standard indicators are somewhat adjusted. Lifetime prevalence concerns ever use up to last year, last year prevalence concerns the use last year up to last month, last month prevalence concerns the use during last month. As shown in Table 2 for males tobacco lifetime prevalence increases with age. From 45 years onwards at least $85 \%$ of the males has ever smoked. For females there is an increase up to the age category 46 to 55 years. At higher ages less females have ever smoked, a phenomenon that is clearly a cohort exect. For most age groups last year prevalence is substantially smaller than lifetime prevalence indicating that many individuals that ever smoked have stopped smoking. Since the dixerences between last year prevalence and last month prevalence are small not many individuals have stopped recently. Except for the youngest and the oldest there is not much dixerence between the age groups in terms of last year or last month prevalence of tobacco. For alcohol the three indicators are not very much dixerent and with the exception of the oldest group of females none of the prevalence indicators is very much dixerent across the age groups. A pparently, the use of alcohol is a phenomenon that does not dixer a lot between population groups.

A frequently used indicator to distinguish between regular use and incidental use is whether an individual that has ever used alcohol or tobacco has done this more than 25 times. Table 3 gives an overview of this intensity of use indicator again distinguished by gender and age group. For tobacco the high intensity of use indicator is substantially below the lifetime prevalence indicating that a lot of individuals have smoked tobacco in the past but not very frequently. For alcohol the high intensity of use indicator is not much dixerent from the lifetime prevalence indicating that those that use alcohol do this on a very regular basis.

Finally, an important indicator of the use of alcohol and tobacco is what individuals indicate as 'normal' use. To illustrate this I use the following ...ve categories for tobacco based on what is reported as the number of cigarettes, cigars or pipes the individual 'normally' smokes during a day: 0, 1-2, 3-10, 11-20, 20+. For alcohol I use eight categories based on what is reported as the number of glasses of alcohol (beer, wine, genever) the individual 'normally' drinks during a period of 30 days i.e. a month:4 $0,1-5,6-16,17-31,32-62,63-93,94-124$ and 125 or more

\footnotetext{
${ }^{4}$ These categories are also used in Zarkin et al. (1998). A nother way to interpret
} 
drinks. In this paper I focus on individuals from 26 to 55 years. A mong individuals below this age range as well as among individuals above this age range there are many non-participants. Table 4 shows for the age group 26 to 55 years the distribution smoking and drinking distinguished by gender. It appears that about $60 \%$ of the males and females in the sample do not smoke anymore or have never smoked. Between males and females there is not a big dixerence in the distribution of smoking intensity. Of the males $8 \%$ smokes more than 20 cigarettes per day, for females this concerns $5 \%$ of the sample. Table 4 also indicates that for those that smoke, the average number of cigarettes per day is about 13.

For alcohol the dixerences in use between males and females are larger. Of the males 7\% indicate not to drink, while for females this is $16 \%$. On the other hand $40 \%$ of the males indicate to drink on average at least one glass per day, while for females only $20 \%$ indicate doing this. The average use for those that drink is a little over 1.5 glass of alcohol per day for males, while for females it is a little less than 1 glass of alcohol per day.

\section{A lcohol and tobacco use}

\subsection{Starting rates}

In the study of the use of alcohol and tobacco I begin with starting rates. For this I apply hazard rate analysis, a technique that is frequently used in the analysis of labor market dynamics. Figure 1 shows the empirical starting rates. Figure la shows that most of the action in terms of starting to smoke is between age 14 and 19 . The peak in the starting rate for females is at age 16, when almost $20 \%$ of the females that did not start smoking until then started smoking at that age. For males there are peaks at ages 15,16 and 18 , with starting rates of almost $20 \%$. Figure $1 \mathrm{~b}$ shows that also for starting to drink most of the action is in the age range from 14 to 19 . The dip at age 11 is due to the fact that the (few) individuals that indicated to have started drinking below age 10 are assumed to have started at age 10 . For males there is a peak in the starting rate at age 16, when more than $50 \%$ that have not started until then start drinking alcohol at that age. For females there are peaks in the alcohol starting rates of more than $30 \%$ at age 16 and 18 .

The starting point in the current analysis is the mixed proportional hazard model with a fexible baseline hazard. Dixerences between individuals in the rates by which they start using alcohol and tobacco are

these categories is: 0 , up to 1 drink per week, from 1 drink per week up to 1 drink every other day, from 1 drink every other day up to 1 drink per day, 1 to 2 drinks per day, 2 to 3 drinks per day, 3 to 4 drinks per day and 4 or more drinks per day. 
assumed to be related to observed characteristics, the elapsed duration of time they are exposed to potential use and unobserved characteristics. I take age 10 to be the time at which the potential exposure to alcohol and tobacco starts.

The starting rate for alcohol, at time $t$ conditional on observed characteristics $x$ and unobserved characteristics $v_{a}$ is speci..ed as

$$
\mu_{a}\left(\mathrm{t} \mathrm{j} x ; v_{a}\right)=\text {,a }_{a}(\mathrm{t}) \exp \left(\mathrm{x}^{0^{-}}{ }_{\mathrm{a}}+\mathrm{v}_{\mathrm{a}}\right)
$$

where, a $(t)$ represents individual duration (age) dependence and ${ }^{-}{ }_{a}$ represents a vector of coec cients. I model ‡exible duration dependence by using a step function:

$$
\text { , } a(t)=\exp \left(\S_{k}, a ; k l_{k}(t)\right)
$$

where $\mathrm{k}(=1, \ldots, 11)$ is a subscript for age-interval and $I_{k}(t)$ are timevarying dummy variables that are one in subsequent age-intervals. I distinguish 11 age intervals of which 10 are of one year (age 10, 11,.., 19) and the last interval is open: , 20 years. Because I also estimate a constant term, I normalize , a; $1=0$.

The starting rate for tobacco is modelled in the same way

$$
\mu_{b}\left(t j x ; v_{b}\right)={ }_{b}(t) \exp \left(x^{0-}{ }_{b}+v_{b}\right)
$$

The conditional density functions of the completed durations of non-use can be written as

$$
f_{j}\left(t j x ; v_{j}\right)=\mu_{j}\left(t j x ; v_{j}\right) \exp \left(i{ }_{0}^{Z_{t}} \mu_{j}\left(s j x ; v_{j}\right) d s\right) \quad \text { for } j=a ; b
$$

I take the possible correlation between the unobserved components in the starting rates for alcohol and tobacco into account by specifying the joint density function of the two durations of non use $t_{a}$ and $t_{b}$ conditional on $x$ as

$$
h\left(t_{a} ; t_{b} j x\right)={ }_{u}^{Z} f_{a}\left(t_{a} j x ; v_{a}\right) f_{b}\left(t_{b} j x ; v_{b}\right) d G\left(v_{a} ; v_{b}\right)
$$

I model the joint distribution of unobserved heterogeneity assuming a discrete distribution $\mathrm{G}\left(\mathrm{v}_{\mathrm{a}} ; \mathrm{v}_{\mathrm{b}}\right)$ where both unobserved components have two points of support that are perfectly correlated. This implies that I assume that random exects infuence the starting rates, i.e. there are two types of individuals that dixer in their inclination towards the use of alcohol and tobacco: ${ }^{5}$

$$
\operatorname{Pr}\left(\mathrm{v}_{\mathrm{a}}=\mathrm{v}_{1 ; \mathrm{a}} ; \mathrm{v}_{\mathrm{b}}=\mathrm{v}_{1 ; \mathrm{b}}\right)=\mathrm{p}
$$

\footnotetext{
${ }^{5}$ I also tried more $\neq$ exible speci..cations of the joint distribution of unobserved heterogeneity but could not identify additional points of support. This is probability due to the fact that smoking without alcohol use rarely occurs.
} 


$$
\operatorname{Pr}\left(v_{a}=v_{2 ; a} ; v_{b}=v_{2 ; b}\right)=1 ; p
$$

where $p$ is assumed to have a logit speci..cation: $p=\frac{\exp \left({ }^{\circledR}\right)}{1+\exp (\mathbb{B})}$ : The explanatory variables are education and religion. The analysis is done separately for males and females and takes account of the fact that some individuals have not started using alcohol or tobacco at the time of the survey but may start in the future, i.e. their durations of non-use are right-censored. The parameters are estimated using the method of maximum likelihood. The estimation results are shown in Table 5.

For males none of the coec cients of the explanatory variables is different from zero at conventional levels of signi..cance. The pattern of duration dependence reveals that the maximum starting rate for tobacco is at age 18, while for alcohol the maximum starting rate is at age 16. Both starting rate have two mass points. For tobacco one of the mass points goes to minus in..nity which indicates that there is a group of men that will never start smoking. For alcohol the second mass point is signi..cantly lower than the ..rst mass point. ${ }^{6}$ The parameter of the mass point distribution indicates that - conditional on the observed characteristics and the pattern of duration dependence - there is a group representing $87 \%$ of the men, which have positive starting rates for both tobacco and alcohol. The remaining group of $13 \%$ of the men have a low starting rate for alcohol and a zero starting rate for tobacco.

For females education is negatively related to the starting rate for tobacco and positively related to the starting rate of alcohol. Furthermore, Catholic and Protestant females are less likely to start smoking than females with no religion or a dixerent type of religion. Conditional on their observed characteristics, the peak of the female starting rates for tobacco and alcohol is at age 16. Conditional on the observed characteristics and the age dependence there is no clear evidence of the presence of unobserved characteristics. The second mass point for the alcohol starting rate is not signi..cantly dixerent from the ..rst one and when ignoring the presence of unobserved heterogeneity the value of the loglikelihood does not change very much. ${ }^{7}$

\footnotetext{
${ }^{6}$ The Likelihood Ratio test statistic comparing a model with and without unobserved heterogeneity is equal to 17.4 , which would be signi..cant at a $1 \%$ level and 3 degrees of freedom (the critical $\hat{A}_{0: 01}^{2}=11: 3$ ). However, note that a formal $L R i$ test is problematic since one of the parameters $(p)$ is not identi..ed under the null hypothesis.

${ }^{7} \mathrm{~T}$ he formal LR test statistic $=5.6$, which would not be dixerent from zero at a $5 \%$-level of signi..cance.
} 


\subsection{Current use of alcohol and tobacco}

The empirical analysis continues with an investigation of the determinants of the intensity of current use concerning tobacco and alcohol. The intensity of use is assumed to depend on personal characteristics and whether or not an individual started using tobacco or alcohol early on, that is before the age of 16 :

$$
\ln \left(\mathrm{y}_{\mathrm{ji}}+1\right)={ }^{-}{ }_{\mathrm{j} 0}+{ }^{-}{ }_{\mathrm{j} 1} \mathrm{x}_{\mathrm{i}}+{ }^{-}{ }_{\mathrm{j} 2} \mathrm{z}_{\mathrm{ji}}+{ }_{\mathrm{ji}} \quad \text { for } \mathrm{j}=\mathrm{a} ; \mathrm{b}
$$

where $y$ is the intensity of use of tobacco or alcohol of person $i$. The logarithmic speci...cation reduces the inłuence of outliers, accounts for non-linearity and for the fact that the intensity of use is non-negative. Furthermore, $x$ represents a vector of personal characteristics like age, education, family position and religion, $z$ represents early alcohol or tobacco use, ${ }^{-}$are parameters of interest and " is the error term.

Although equation (7) is linear the coet cients are estimated using maximum likelihood to account for correlation between "ai and " ${ }_{b}$, where $1 /$ is the correlation coe cient. ${ }^{8}$ Table 6 shows the estimation results. For males age has a positive exect on tobacco use although the coed cient is signi..cant only at the $10 \%$ level. This is probably related to a cohort exect. Higher educated males with partners smoke less than their counterparts do. The presence of children in the family does not axect the smoking behavior of males. Finally, males that start early, i.e. begin smoking before age 16 have a signi..cant higher tobacco use than individuals that start later on (or do not start at all). Religion does not axect smoking behavior. Concerning alcohol use of males only age and early start have a (positive) exect. The correlation between the error terms is signi..cantly positive indicating that conditional on their observed characteristics those that drink a lot are also likely to smoke a lot.

By and large females have similar determinants. Females smoke more if they are low educated, have no partner or were an early smoker. They drink more at higher age and if they started drinking early in life. Catholic and Protestant females drink less than females without religion or with a dixerent type of religion, while religion does not axect smoking behavior. Here too there is a positive correlation between the error terms.

\footnotetext{
${ }^{8}$ Regional dummies or dummies for urbanization are jointly insigni..cant and do not infuence the parameter estimates.
} 


\section{Wage exects of tobacco and alcohol use}

\subsection{OLS parameter estimates}

To investigate the exect of the use of alcohol and tobacco on wages I use a restricted dataset of which the main characteristics are also shown in the A ppendix. The hourly wage is calculated as the ratio of personal income and number of working hours. I restricted the sample to individuals indicating to work between 10 and 60 hours per week. ${ }^{9}$ Furthermore, I only used information about individuals for which the hourly wage was at least 10 guilders. ${ }^{10}$ As shown in Table A 2 the average hourly wages are about 33 guilders for males and 29 guilders for females. The wage equations are speci..ed as:

$$
\ln \left(w_{i}\right)={ }_{0}^{0}+{ }_{1}^{\circ} x_{i}+{ }^{\circ}{ }_{2} f_{a i}+{ }^{\circ}{ }_{3} f_{i}+{ }_{i}
$$

where $\mathrm{w}$ represents hourly wage, $\mathrm{x}$ represents personal characteristics (age and education) and $\wp_{a}$ and $\varphi_{a}$ are indicators of the intensity of tobacco and alcohol use. Furthermore, ${ }^{2}$ is the error term of which I initially assume that it is i.i.d. and ${ }^{\circ}$ is the vector of parameters of interest.

I start with estimates in which the indicator of tobacco and alcohol use are speci..ed using a number of dummy variables representing the categories speci..ed in Table $4 .{ }^{11}$ The estimation results are shown in Table 7. It appears that age has a positive exect on the wages of both males and females. For every year they grow older male wage increases with $1.3 \%$, while females experience an annual wage increase of $0.7 \%$. High educated individuals earn about $36 \%$ more than individuals without education. Tobacco use has a negative exect on the hourly wage rate of males, although only for the category 3 to 10 cigarettes per day this exect is signi..cant from zero. For this category the hourly wage is about $12 \%$ lower than it is for non-smokers. Alcohol use has a positive exect on the male wage rate, although for the category 1-5 glasses per month and more than 120 glasses per month the exect does not dixer signi... cantly from zero. The peak of the exect is for the category $61-90$ glasses per month, which has a wage that is about $27 \%$ higher than wages on non-drinkers. For females there is no exect of alcohol or tobacco use. The exception is the category of heavy drinkers that has a wage that is

\footnotetext{
${ }^{9}$ One individual indicated to work 120 hours per week.

${ }^{10} \mathrm{~A}$ guilder is equivalent to $0.44 \mathrm{E}$ uro.

${ }^{11}$ To account for possible selection bias due to the fact that not every individual in the sample has a job I added Heckman's sample selection term but did not ..nd a signi..cant parameter connected to this term.
} 
$26 \%$ higher than the wage of non-drinking females, although the relevant coec cient is only signi...cant at a $10 \%$-level.

From Table 7 I conclude that for males wages are axected by both smoking and drinking while for females this does not seem to be the case. Furthermore, it seems as if the exect of both alcohol and tobacco on the wages of males is nonlinear. To investigate this in more detail I distinguish two speci..cations of use. The ..rst and third column of Table 8 report OLS estimates of wage equations in which tobacco use and alcohol use are speci..ed as continuous variables: ${ }_{a i}=\ln \left(y_{a i}+1\right) ; y_{a i}=$ $\ln \left(y_{b i}+1\right)$ : In other words the dependent variables in (1) are explanatory variables in (2). The coet cients of age and education are almost the same as those in Table 7. Tobacco use has a signi..cant negative exect and alcohol use has a signi..cant positive exect on the hourly wage of males. The parameter estimates for females wages indicate that tobacco use has no exect, while alcohol use has a positive exect. This latter exect has to do with the large positive wage exect of heavy drinking (see Table 7).

The second and fourth column of Table 8 concern wage equations where tobacco use and alcohol use are speci..ed as dummy variables: $y_{a i}=I\left(y_{a i}>0\right) ; y_{b i}=1\left(y_{b i}>0\right)$ : The parameter estimates show that conditional on their other characteristics males that smoke have an hourly wage that is about $6 \%$ lower than that of non-smokers. Alcohol drinkers have a wage that is about $13 \%$ higher than the wage of abstainers. ${ }^{12}$ Female wages are not axected by alcohol or tobacco use.

\subsection{Correcting for unobserved heterogeneity}

Although it seems as if drinking has a positive exect on male wages and smoking has a negative exect it cannot be ruled out the there are unobserved determinants that simultaneously axect smoking, drinking and wages. If that is the case it could be that the true causal exects dixer from the exects presented in the previous subsection. To account for the exects of unobserved heterogeneity and possible endogeneity of smoking and drinking I used traditional 2SLS and 3SLS estimation procedures. The results presented in A ppendix 2 indicate that for females I do not ...nd a signi..cant wage exect. For males the wage exects of alcohol use become implausibly high. As discussed in the introduction this is a phenomenon that occurs in a lot of other studies too.

A pparently, it is diф cult to ..nd good instrumental variables. There-

\footnotetext{
${ }^{12}$ I tried whether smoking 1-2 cigarettes per day or drinking heavily contributed to the explanation of the wage but in neither case I found signi..cant coed cients. I also investigated whether the size of the exects of smoking and drinking is related to the educational level but found no evidence of this.
} 
fore, to investigate the exect of unobserved characteristics I use an alternative approach where I combine the information derived from estimating starting rates to estimate wage equations with unobserved heterogeneity accounted for:

$$
\begin{gathered}
\ln \left(w_{a ; i}\right)={ }_{0}^{\circ}+{ }_{1}^{\circ} x_{i}+{ }_{2}^{\circ} y_{1 i}+{ }_{3}^{\circ} f_{2 i}+{ }_{i} \\
\ln \left(w_{b ; i}\right)=\ln \left(w_{a ; i}\right)+{ }_{0}^{\circ x}
\end{gathered}
$$

where, if ${ }_{0}^{\circ x} \in 0$, there is unobserved heterogeneity in the wages. In combination with the starting rate analysis, it is possible to identify ${ }_{0}^{\circ x}$ and relate unobserved heterogeneity in the starting rates to unobserved heterogeneity in the wage equation:

$$
\begin{gathered}
\operatorname{Pr}\left(v_{a}=v_{1 ; a} ; v_{b}=v_{1 ; b} ; \stackrel{\circ a}{0}=0\right)=p \\
\operatorname{Pr}\left(v_{a}=v_{2 ; a} ; v_{b}=v_{2 ; b} ; \stackrel{\circ \alpha}{0} \in 0\right)=1 ; \quad p
\end{gathered}
$$

The estimation results shown in Table 9 indicate that the second mass point in the wage equation is signi..cantly smaller than zero. ${ }^{13}$ This implies that males that are inclined to drinking and smoking have a higher wage than otherwise similar individuals that do not have a strong inclination to drink alcohol and have a zero starting rate for tobacco use. Therefore, OLS overestimates the positive wage exect of alcohol and underestimates the negative wage exect of tobacco. The parameter estimates in Table 9 under (1) imply that for an average drinker wages are $6.7 \%$ above the wage of an otherwise identical abstainer, while an average smoker has a wage $8.7 \%$ below the wage of an otherwise identical non-smoker. Due to the logarithmic speci..cation of the use-variable there are decreasing returns to drinking and smoking. An individual that drinks twice the average has a wage bonus of $7.8 \%$ while an individual that smokes twice the average faces a wage penalty of $11.9 \%$. The parameter estimates in Table 9 under (2) imply that a drinker has a wage that is $9.8 \%$ higher than an otherwise identical non-drinker while a smoker has a wage that is $9.0 \%$ lower than an otherwise identical nonsmoker. ${ }^{14}$ For both estimates it holds that the positive exect of drinking

\footnotetext{
${ }^{13}$ The LR-statistic for ${ }_{0}^{\circ \alpha}=0$ is signi..cant at a $1 \%$ level in both models. The critical $\hat{A}_{0: 01}^{2}$ for 1 degree of freedom is 6.63 . The LR-test statistic for ${ }_{0}^{\circ \alpha}=0$ under (1) equals 6.56, and under (2) equals 7.86. I also investigated whether I could identify a third mass point in the distribution of unobserved heterogeneity but did not succeed to do so. Note that Table 9 only contains estimates for males. For females I did not ..nd that alcohol use or tobacco use in $\ddagger$ uence the wage.

${ }^{14} \mathrm{~T}$ he coec cient of alcohol use is on the borderline of signi...cance. This has to do with the substantial variation in the wages of males that are mild users of alcohol. If I respecify the dummy for alcohol use to cover the range above 2 drinks per month I ..nd a coec cient of 0.073 with an absolute t-statistic of 2.2.
} 
is about the same as the negative exect of smoking. Or in other words: smoking cancels out the positive wage exects of drinking.

\section{Conclusions}

This paper deals with the exects of the use of tobacco and alcohol on wages. The data are from a December 2001 survey in the Netherlands. From the analysis it appears that the wages of females are not axected by smoking and drinking. For males smoking has a negative exect on wages while drinking has a positive exect. The size of the exect is almost independent of the intensity of smoking or drinking. I use an alternative method to account for possible joint unobserved determinants of the use of alcohol and tobacco and the level of the wage. It appears that there are unobserved characteristics of individuals that cause dixerences in earnings between smokers and non-smokers and between drinkers and non-drinkers. Ceteris paribus non-drinkers and non-smokers earn less than drinkers and smokers do. This means that with OLS the positive wage exect of drinking is over-estimated while the negative exect of smoking is under-estimated. Taking the exect of unobserved heterogeneity into account I ..nd that alcohol users earn about 10\% more than non-drinkers while non-smokers earn about $10 \%$ less than smokers do. All in all, it seems fair to say that alcohol use increases the wage, but smoking takes that wage gain away. 


\section{R eferences}

[1] Auld, M.C. (1998) Wage, alcohol use, and smoking: simultaneous estimates, Department of Economics Discussion Paper No. 98/08, University of Calgary.

[2] Berger, M.C., and Leigh, J.P. (1988) The exect of alcohol use on wages, A pplied E conomics, 20, 1343-1351.

[3] Dave, D. and R. Kaestner (2002) Alcohol taxes and labor market outcomes, J ournal of Health Economics, 21, forthcoming.

[4] French, M.T . and Zarkin, G.A. (1995) Is moderate alcohol use related to wages? Evidence from four worksites, J ournal of Health Economics, 14, 319-344.

[5] Hamilton, V and Hamilton, B.H. (1997) Alcohol and earnings: does drinking yield a wage premium? Canadian J ournal of Economics, 30, 135-151.

[6] Heien, D.M. (1996) Do drinkers earn less? Southern E conomic J ournal, 63, 60-68.

[7] Lee, Y . (1999) Wage exects of drinking and smoking: an analysis using A ustralian twins data, University of Western A ustralia W orking Paper, 99-22.

[8] Leigh, J . (1995) Smoking, self-selection and absenteeism, Quarterly Review of E conomics and Finance, 35, 365-386.

[9] Levine, P.B., Gustafson, T.A. and Valenchik, A.D. (1997) More bad news for smokers? The exects of cigarette smoking on wages, Industrial and Labor Relations Review, 50, 493-509.

[10] Lye, J.M., and Hirschberg, J.G. (2001) Alcohol, consumption, smoking and wages, Discussion Paper, Department of Economics, University of Melbourne.

[11] MacDonald, Z. and S. Pudney (2000) Illicit drug use, unemployment, and occupational attainment, J ournal of Health Economics, 19, 1089-1115.

[12] MacDonald, Z. and Shields, M. (2001) The impact of alcohol use on occupational attainment in England, Economica, 68, 427-454.

[13] Mullahy, J. and Sindelar, J.L. (1991) Gender dixerences in labor market exects of alcoholism, American Economic Review, 81, 161165.

[14] Van den Berg, G.J . (2001) Duration models: speci..cation, identi... cation, and multiple durations, in: Heckman, J J ., and E. Leamer (eds.), Handbook of E conometrics, Volume V, North-Holland, forthcoming.

[15] Zarkin, G .A., French, M .T ., M roz, T . and B ray, J .W . (1998) A Icohol use and wages: new results from the National Household Survey on drug abuse, J ournal of Health E conomics, 17, 53-68. 


\section{A ppendix 1: Information about the data}

\subsection{CentER-data data}

CentER-data exploits an Internet-based panel consisting of some 2000 households in the Netherlands. Every week, the panel members ...l in a questionnaire on the Internet, while being at home. The CentE R panel is representative of the Dutch population in terms of age, sex, religion, education, region, and province. The data on the use of alcohol and tobacco were collected in the week before Christmas 2001. The questions about smoking and drinking are questions typically asked like lifetime prevalence, last year prevalence, last month prevalence, frequency of use ever, normal current use. The data about the personal characteristics and labor market position were drawn from the available information about the panel members.

\subsection{De..nition of variables}

In the analysis the following explanatory variables are used:

2 A ge: A ge of individuals at the time of the survey.

2 Primary education: Dummy variable with a value of 1 if the individual attended extended primary education after having attended basic education, and a value of 0 otherwise.

2 Secondary education: Dummy variable with a value of 1 if the individual attended secondary general or vocational education, and a value of 0 otherwise. Secondary education refers to intermediate vocational or secondary general education.

2 Higher education: Dummy variable with a value of 1 if the individual attended higher vocational or academic education, and a value of 0 otherwise. Since there are three dummy variables for education the overall reference group consists of individuals with only basic education.

2 Children: Dummy variable with a value of 1 if the individual has children and a value of 0 otherwise.

2 Partner: Dummy variable with a value of 1 if the individual has a partner and a value of 0 otherwise.

2 Catholic: Dummy variable with a value of 1 if the individual indicates to be Catholic and a value of 0 otherwise. 
2 Protestant: Dummy variable with a value of 1 if the individual indicates to be Protestant and a value of 0 otherwise.

2 E arly start tobacco (alcohol) use: Dummy variable with a value of 1 if the individual indicated to have started using tobacco (alcohol) before the age of 16 .

2 Intensity of tobacco use: number of cigarettes, cigars or pipes the individual 'normally' smokes during a day.

2 Intensity of alcohol use: number of glasses of alcohol (beer, wine, genever) the individual 'normally' drinks during a month.

2 lifetime prevalence: based on the question: did you ever use (tobacco, alcohol) up to last year?

2 Last year prevalence: based on the question: did you use (tobacco, alcohol) last year (up to last month)?

2 Last month prevalence: based on the question: did you use (tobacco, alcohol) last month?

2 Hourly wage calculated as the individual gross monthly income divided by the monthly hours of work (= weekly hours of work $* 13 / 3)$

Tables A 1 and A 2 present the characteristics of the full dataset and the dataset used in the wage regressions. 


\section{A ppendix 2: 2SLS and 3SLS estimates}

In search for instrumental variables, i.e. variables that axect drug use but do not directly arect wages, I use the estimation results presented in Table 6. From this table it appears that 'partner' and 'early start' axect both tobacco use and alcohol use. I assume that these variables do not directly axect the wage rate so they can be used as instruments for alcohol use and tobacco use. The ..rst and third column of Table A 3 present 2SLS estimates. It appears that after accounting for potential endogeneity tobacco use has a negative exect on male wages while alcohol use has a positive exect. However, the estimated coec cient for tobacco is 3 times as large as the OLS estimates presented in Table 8 (although insigni..cantly dixerent from zero), while this is 5 times as large for the exect of alcohol. So, like previous studies I ..nd that 2SLSestimates generate a huge increase in the estimated exect of alcohol on male wages. A pparently, the instruments I use are not valid. It is possible that contrary to what I assumed there are unobserved characteristics of individuals that infuence both their early start of smoking and drinking as well as their wage. For females I do not ..nd that the coec cients for alcohol or tobacco dixer signi..cantly from zero. Auld (1998) stresses that it is important to take simultaneity into account. Wage (or rather income) axects the use of alcohol and tobacco as well as the other way around. If alcohol is a normal good and tobacco is an inferior good and they are nevertheless treated as exogenous alcohol will have a positive exect on wages and tobacco a negative exect. To take account of this feedback mechanism I performed 3SLS estimates of which the results are presented in the second and fourth column of Table A3. A gain, for males smoking has a negative wage exect and drinking has a positive exect. Note that the size of the exects is again substantially larger than the OLS parameter estimates. Apparently estimating an entire system does not provide more plausible estimates of the wage exects of smoking and drinking than 2SLS does. For females I again ..nd no wage exects of alcohol and tobacco use. ${ }^{15}$ Finally, note that Table $A 3$ only presents parameter estimates of wage equations in which tobacco and alcohol use are speci..ed as continuous variables. When speci..ed as dummy variables 2SLS and 3SLS parameter estimates for males are also 5-6 times as large as OLS estimates. For females I again ..nd no signi..cant exects of tobacco and alcohol use.

\footnotetext{
${ }^{15}$ Table $A 3$ does not presents the parameter estimates for the alcohol use and the tobacco use equation. I ..nd that wages have a positive exect on alcohol use and a negative exect on the use of tobacco. For males the earnings elasticity of alcohol use is approximately 0.9 , while the earnings elasticity of tobacco use is about -0.7 . For females I ..nd earnings elasticities for alcohol of 1.2 and for tobacco of -2.1 .
} 
Table A 1 General characteristics of the full dataset

\begin{tabular}{|c|c|c|c|c|c|c|c|c|}
\hline & \multicolumn{4}{|c|}{ Males } & \multicolumn{3}{|c|}{ Females } & \\
\hline & M ean & Min & Max & $\mathrm{N}$ & Mean & Min & Max & \\
\hline $\begin{array}{l}\text { A ge } \\
\text { Education }\end{array}$ & 48.5 & 16 & 86 & 1010 & 44.5 & 16 & 86 & 82 \\
\hline Primary & 0.19 & 0 & 1 & 1010 & 0.25 & 0 & 1 & \\
\hline Secondary & 0.35 & 0 & 1 & 1010 & 0.37 & 0 & 1 & \\
\hline Higher & 0.41 & 0 & 1 & 1010 & 0.29 & 0 & 1 & \\
\hline Family & & & & & & & & \\
\hline Children & 0.38 & 0 & 1 & 1010 & 0.44 & 0 & 1 & \\
\hline $\begin{array}{l}\text { Partner } \\
\text { Religion }\end{array}$ & 0.77 & 0 & 1 & 1010 & 0.76 & 0 & 1 & \\
\hline Catholic & 0.34 & 0 & 1 & 1010 & 0.33 & 0 & 1 & \\
\hline P rotestant & 0.20 & 0 & 1 & 1010 & 0.21 & 0 & 1 & \\
\hline Drug use & & & & & & & & \\
\hline Early start tobacco & 0.50 & 0 & 1 & 740 & 0.42 & 0 & 1 & \\
\hline Early start alcohol & 0.37 & 0 & 1 & 915 & 0.32 & 0 & 1 & \\
\hline Tobacco use & 12.5 & 1 & 125 & 408 & 13.1 & 1 & 40 & \\
\hline $\begin{array}{l}\text { Alcohol use } \\
\text { lifetime prevalence }\end{array}$ & 49.0 & 1 & 600 & 912 & 26.7 & 1 & 600 & \\
\hline Tobacco & 0.76 & 0 & 1 & 1003 & 0.61 & 0 & 1 & \\
\hline Alcohol & 0.98 & 0 & 1 & 1000 & 0.92 & 0 & 1 & \\
\hline Last year prevalence & & & & & & & & \\
\hline Tobacco & 0.32 & 0 & 1 & 1003 & 0.29 & 0 & 1 & \\
\hline Alcohol & 0.92 & 0 & 1 & 1000 & 0.84 & 0 & 1 & \\
\hline Last month prevalence & & & & & & & & \\
\hline Tobacco & 0.32 & 0 & 1 & 1003 & 0.28 & 0 & 1 & \\
\hline Alcohol & 0.89 & 0 & 1 & 1000 & 0.77 & 0 & 1 & \\
\hline & & & & & & & & \\
\hline Hourly wage & 69.0 & 0 & 2163.5 & 706 & 33.6 & 0 & 757.2 & \\
\hline
\end{tabular}


Table A 2 General characteristics of the dataset used in the wage regressions

\begin{tabular}{|c|c|c|c|c|c|c|c|c|}
\hline & & $\mathrm{Mal}$ & & & & emales & & \\
\hline & Mean & Min & Max & $\mathrm{N}$ & Mean & Min & $\operatorname{Max}$ & $\mathrm{N}$ \\
\hline Age & 41.4 & 26 & 55 & 508 & 38.5 & 26 & 55 & 336 \\
\hline E ducation & & & & & & & & \\
\hline Primary & 0.17 & 0 & 1 & 508 & 0.14 & 0 & 1 & 336 \\
\hline Secondary & 0.38 & 0 & 1 & 508 & 0.42 & 0 & 1 & 336 \\
\hline Higher & 0.42 & 0 & 1 & 508 & 0.42 & 0 & 1 & 336 \\
\hline Family & & & & & & & & \\
\hline Children & 0.54 & 0 & 1 & 508 & 0.49 & 0 & 1 & 336 \\
\hline Partner & 0.75 & 0 & 1 & 508 & 0.72 & 0 & 1 & 336 \\
\hline Religion & & & & & & & & \\
\hline Catholic & 0.30 & 0 & 1 & 508 & 0.30 & 0 & 1 & 336 \\
\hline Protestant & 0.18 & 0 & 1 & 508 & 0.17 & 0 & 1 & 336 \\
\hline Drug use & & & & & & & & \\
\hline Early start tobacco ${ }^{a)}$ & 0.52 & 0 & 1 & 355 & 0.44 & 0 & 1 & 201 \\
\hline Early start alcohola) & 0.47 & 0 & 1 & 462 & 0.40 & 0 & 1 & 285 \\
\hline Tobacco use ${ }^{b)}$ & 11.9 & 1 & 45 & 211 & 13.1 & 1 & 40 & 119 \\
\hline Alcohol use ${ }^{b)}$ & 45.5 & 1 & 600 & 474 & 26.6 & 1 & 600 & 287 \\
\hline Wage & & & & & & & & \\
\hline Hourly wage & 33.4 & 14.4 & 89.6 & 508 & 29.0 & 11.0 & 73.4 & 336 \\
\hline
\end{tabular}


Table A 3 Estimation results wage regressions males and females, age 26-55 years (2SLS and 3SLS) a)

$2 S L S^{\text {b) }} \stackrel{\text { Males }}{3 S L S^{c}} \quad 2 S L S^{\text {b) }} \quad 3 S L S^{c}$

\begin{tabular}{|c|c|c|c|c|}
\hline $\begin{array}{l}\text { A ge } \\
\text { Education }\end{array}$ & $0.011(4.8)$ & $0.011(4.7)$ & $0.007(2.5)$ & $0.007(2.4)$ \\
\hline & $-0.010(0.1)$ & $0.055(0.8)$ & $0.081(0.6)$ & $0.070(0.5)$ \\
\hline & & & & \\
\hline $\begin{array}{l}\text { igher } \\
\text { obacco use }\end{array}$ & & 4) & 0.41 & \\
\hline $\begin{array}{l}\text { o./ day } \\
\text { Icohol use }\end{array}$ & $-0.126(2.3)$ & $-0.070(1.6)$ & $0.047(0.8)$ & $0.067(1$. \\
\hline 0.1 & & & & \\
\hline & & & $2.737(17.0)$ & \\
\hline & 0.180 & 0.200 & 0.171 & 0.149 \\
\hline
\end{tabular}

a) A bsolute t-values in parentheses.

b) Instruments used for tobacco use and alcohol use are 'partner', 'early start alcohol use', 'early start tobacco use' and the other exogenous variables.

c) The equation for tobacco use contains a constant and 'age', 'partner', 'higher education', 'early start tobacco use'; the equation for alcohol use contains a constant and 'age', 'higher education', 'early start alcohol use'; the instruments are a constant, the three educational dummies, 'age', 'partner', 'early start alcohol use', 'early start tobacco use'; the parameter estimates of the alcohol use equation and the tobacco use equation are not shown.

d) $\mathrm{Ln}$ (use+1) as continuous variable 
Table 1 Labor market situation by age category and gender

$\begin{array}{cccccc}\text { M ales } & \begin{array}{c}\text { Employed } \\ (\%)\end{array} & \begin{array}{c}\text { Unemployed } \\ (\%)\end{array} & \begin{array}{c}\text { Non-participants } \\ (\%)\end{array} & \begin{array}{c}\text { Total } \\ (\%)\end{array} & \begin{array}{c}\text { Total } \\ \text { (Number) }\end{array} \\ 16-25 \text { yrs } & 54 & 3 & 43 & 100 & 37 \\ 26-35 \text { yrs } & 95 & 2 & 3 & 100 & 168 \\ 36-45 \text { yrs } & 96 & 2 & 2 & 100 & 255 \\ 46-55 \text { yrs } & 88 & 3 & 9 & 100 & 236 \\ 56-65 \text { yrs } & 39 & 2 & 59 & 100 & 150 \\ 65+\text { yrs } & 2 & 1 & 97 & 100 & 164 \\ \text { Total } & 69 & 2 & 29 & 100 & 1010 \\ \text { Females } & & & & & \\ 16-25 \text { yrs } & 53 & 6 & 41 & 100 & 51 \\ 26-35 \text { yrs } & 86 & 4 & 10 & 100 & 203 \\ \text { 36-45 yrs } & 74 & 3 & 23 & 100 & 221 \\ 46-55 \text { yrs } & 65 & 7 & 28 & 100 & 158 \\ 56-65 \text { yrs } & 17 & 0 & 83 & 100 & 99 \\ 65+\text { yrs } & 2 & 0 & 98 & 100 & 88 \\ \text { Total } & 59 & 3 & 37 & 100 & 820\end{array}$

Table 2 The use of tobacco and alcohol by age group and gender $(\% \text { of total })^{\mathrm{a})}$

Prevalence tobacco Prevalence alcohol

Males

$\begin{array}{cllllll}16-25 \text { yrs } & 32 & 30 & 30 & 97 & 97 & 95 \\ 26-35 \text { yrs } & 57 & 38 & 38 & 96 & 91 & 88 \\ 36-45 \text { yrs } & 67 & 35 & 33 & 96 & 93 & 89 \\ 46-55 \text { yrs } & 85 & 39 & 38 & 98 & 93 & 92 \\ 56-65 \text { yrs } & 85 & 31 & 31 & 99 & 95 & 93 \\ 65+\text { yrs } & 91 & 30 & 15 & 95 & 87 & 84 \\ \text { Females } & & & & & & \\ 16-25 \text { yrs } & 35 & 24 & 20 & 92 & 92 & 84 \\ 26-35 \text { yrs } & 55 & 30 & 27 & 90 & 80 & 70 \\ 36-45 \text { yrs } & 67 & 34 & 33 & 92 & 86 & 79 \\ 46-55 \text { yrs } & 72 & 31 & 30 & 94 & 86 & 79 \\ 56-65 \text { yrs } & 59 & 30 & 30 & 94 & 89 & 87 \\ 65+\text { yrs } & 57 & 24 & 16 & 86 & 77 & 77\end{array}$

a) Lifetime prevalence ever use up to last year; Last year prevalence use during last year up to last month; Last month prevalence use during last month 
Table 3 Intensity of use (more than 25 times ever; \% of total)

\begin{tabular}{ccccc} 
& \multicolumn{2}{c}{ Males } & \multicolumn{2}{c}{ Females } \\
& Tobacco & Alcohol & Tobacco & A lcohol \\
$16-25$ yrs & 30 & 78 & 22 & 65 \\
$26-35$ yrs & 49 & 89 & 44 & 78 \\
$36-45$ yrs & 56 & 89 & 52 & 79 \\
$46-55$ yrs & 65 & 89 & 56 & 83 \\
$56-65$ yrs & 61 & 93 & 44 & 81 \\
$65+$ yrs & 65 & 87 & 38 & 74
\end{tabular}

Table 4 ' $\mathrm{N}$ ormal' use of tobacco and alcohol by males and females; age 26-55 years

\begin{tabular}{cccccc} 
& \multicolumn{2}{c}{ Tobacco } & \multicolumn{3}{c}{ Alcohol } \\
$\mathrm{Nr}$ / day & Males & Females & $\mathrm{Nr}$ month & Males & Females \\
& & & & & \\
0 & 57 & 63 & 0 & 7 & 16 \\
$1-2$ & 11 & 8 & $1-5$ & 15 & 31 \\
$3-10$ & 10 & 9 & $6-16$ & 18 & 18 \\
$11-20$ & 14 & 15 & $17-31$ & 20 & 15 \\
$20+$ & 8 & 5 & $32-62$ & 19 & 11 \\
& & & $63-93$ & 7 & 4 \\
& & & $94-124$ & 8 & 3 \\
Total (\%) & 100 & 100 & $124+$ & 6 & 2 \\
Total (number) & 659 & 582 & & 100 & 100 \\
& & & & 659 & 582 \\
A verage if positive & 13.21 & 13.46 & & 48.78 & 25.60 \\
Overall average & 5.65 & 7.77 & & 45.15 & 21.47
\end{tabular}


Table 5 Starting rates of tobacco and alcohol for males and females; age 26-55 years ${ }^{\text {a) }}$

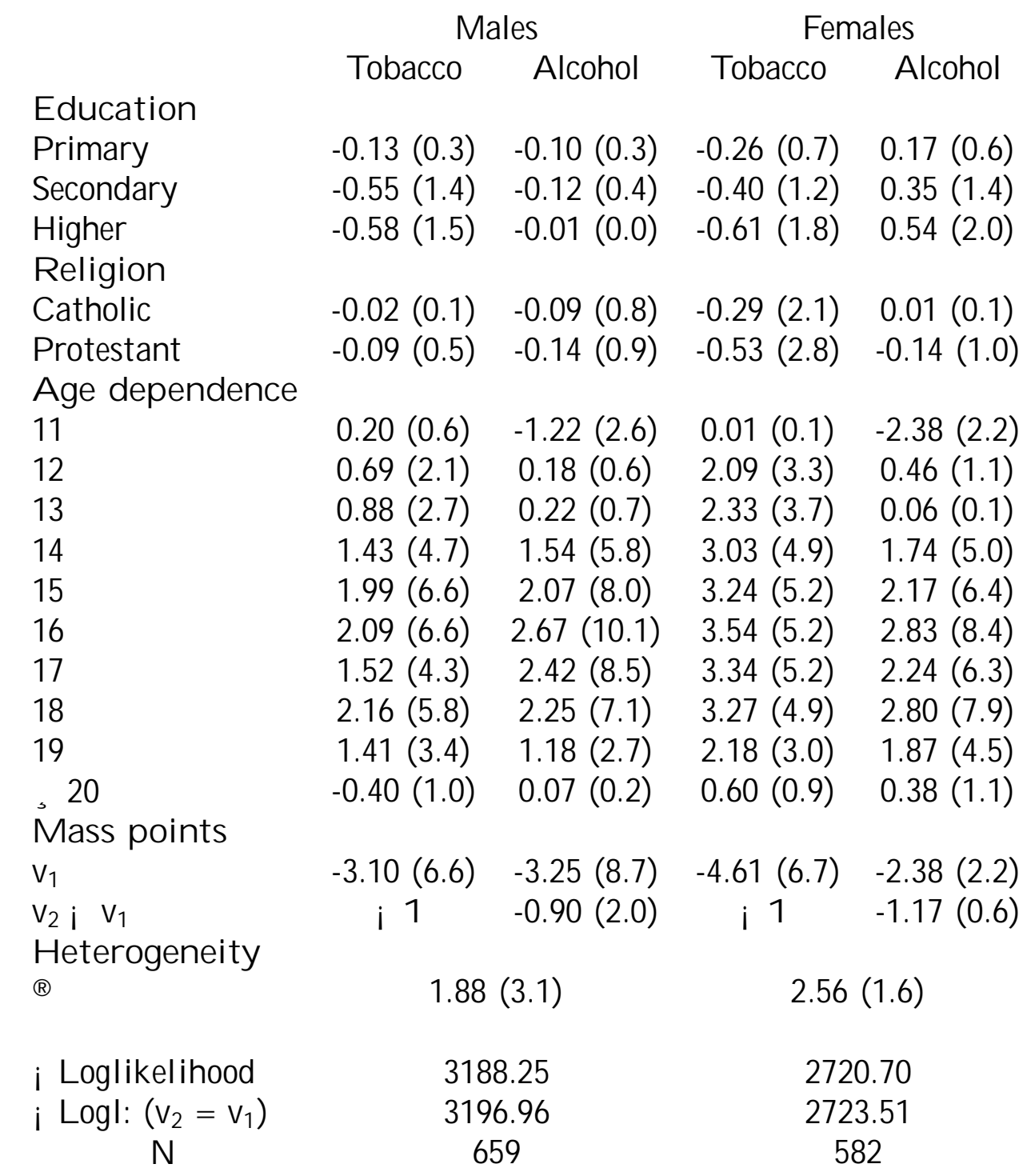

a) absolute t-values in parentheses. 
Table 6 Estimation results intensity of use of tobacco and alcohol by males and females; age 26-55 years ( $M$ aximum Likelihood) a)

\begin{tabular}{|c|c|c|c|c|}
\hline & \multicolumn{2}{|c|}{ Males } & \multicolumn{2}{|c|}{ Females } \\
\hline & Tobacco & Alcohol & Tobacco & Alcohol \\
\hline $\begin{array}{l}\text { A ge } \\
\text { Education }\end{array}$ & $0.012(1.8)$ & $0.036(5.0)$ & $0.007(1.1)$ & $0.042(5.5)$ \\
\hline P rimary & $.41(1.6)$ & $-0.07(0.2)$ & $-0.51(2.1)$ & $0.39(1.4)$ \\
\hline Secondary & $0.33(1.3)$ & $-0.02(0.1)$ & $-0.69(2.8)$ & $0.40(1.5)$ \\
\hline $\begin{array}{l}\text { Higher } \\
\text { Familv }\end{array}$ & $-0.55(2.2)$ & $0.18(0.6)$ & $-1.11(4.0)$ & $0.54(2.0)$ \\
\hline Children & $-0.11(0.9)$ & $-0.08(0.6)$ & $-0.04(0.3)$ & $-0.18(1.4)$ \\
\hline $\begin{array}{l}\text { Partner } \\
\text { Religion }\end{array}$ & $-0.47(3.3)$ & $-0.09(0.6)$ & $-0.44(3.3)$ & $-0.10(0.7)$ \\
\hline Catholic & $-0.03(0.3)$ & $-0.04(0.3)$ & $-0.17(1.5)$ & $-0.30(2.2)$ \\
\hline Protestant & $-0.16(1.1)$ & $-0.06(0.3)$ & $0.02(0.1)$ & $-0.33(2.1)$ \\
\hline Previous use & & & & \\
\hline Early start & $0.55(4.8)$ & $0.51(4.4)$ & $0.70(5.8)$ & $0.78(6.0)$ \\
\hline Constant & $1.14(3.0)$ & $1.36(3.0)$ & $1.52(4.0)$ & $0.09(0.2)$ \\
\hline $1 / 2$ & 0.14 & & 0.20 & \\
\hline i Loglikeli & & & & \\
\hline
\end{tabular}

a) The dependent variable is In(use+1); absolute t-values in parentheses; the $3 / 4$ and $3 / 4$ are not reported. 
Table 7 Estimation results wage regressions for males and females, age 26-55 years (OLS)

\begin{tabular}{|c|c|c|}
\hline & Males & Females \\
\hline $\begin{array}{l}\text { A ge } \\
\text { Education }\end{array}$ & $0.013(7.6)$ & 0.007 (3.3) \\
\hline Primary & $0.032(0.4)$ & $0.077(0.6)$ \\
\hline Secondary & 0.135 (1.7) & 0.139 (1.2) \\
\hline Higher & $0.358(4.6)$ & $0.363(3.1)$ \\
\hline Tobacco use & & \\
\hline $1-2$ & $-0.041(1.1)$ & $0.056(0.8)$ \\
\hline $3-10$ & $-0.118(3.0)$ & $0.020(0.4)$ \\
\hline $11-20$ & $-0.067(1.6)$ & $-0.054(1.3)$ \\
\hline $20+$ & $-0.052(0.8)$ & $-0.006(0.1)$ \\
\hline Alcohol use & & \\
\hline $1-5$ & $0.081(1.3)$ & $-0.010(0.2)$ \\
\hline $6-16$ & $0.152(2.7)$ & 0.071 (1.4) \\
\hline $17-31$ & 0.112 (1.9) & $0.040(0.6)$ \\
\hline $32-62$ & $0.141(2.4)$ & $0.058(0.9)$ \\
\hline $63-93$ & $0.266(4.0)$ & 0.115 (1.4) \\
\hline $94-124$ & $0.166(2.2)$ & 0.129 (1.1) \\
\hline $124+$ & 0.104 (1.3) & 0.259 (1.9) \\
\hline Constant & $2.60(21.1)$ & $2.81(19.8)$ \\
\hline$\overline{\mathrm{R}}^{2}$ & 0.292 & 0.225 \\
\hline $\mathrm{N}$ & 508 & 336 \\
\hline
\end{tabular}

a) A bsolute t-values in parentheses. 
Table 8 Estimation results wage regressions for males and females, age 26-55 years (OLS)

Males

Females

\begin{tabular}{|c|c|c|c|c|}
\hline $\begin{array}{l}\text { A ge } \\
\text { Education }\end{array}$ & $0.014(7.9)$ & $0.014(8.0)$ & $0.007(3.5)$ & $0.008(4.1)$ \\
\hline Primary & $0.023(0.3)$ & $0.027(0.3)$ & $0.083(0.7)$ & $0.087(0.7)$ \\
\hline Secondary & 0.135 (1.7) & $0.136(1.6)$ & $0.138(1.2)$ & $0.148(1.2)$ \\
\hline Higher & $0.353(4.3)$ & $0.360(4.4)$ & $0.361(3.1)$ & $0.381(3.1)$ \\
\hline Tobacco use & & & & \\
\hline No./ dayb) & $-0.024(2.2)$ & - & $-0.009(0.7)$ & - \\
\hline $\begin{array}{l}\left.>0^{c}\right) \\
\text { Alcohol use }\end{array}$ & - & $-0.057(2.3)$ & - & $0.008(0.3)$ \\
\hline No./ monthb) & $0.024(2.5)$ & - & $0.025(2.5)$ & - \\
\hline$>0^{c)}$ & - & $0.134(2.6)$ & - & $0.039(0.9)$ \\
\hline Constant & $2.637(22.9)$ & $2.562(20.6)$ & $2.790(20.7)$ & $2.753(19.5)$ \\
\hline$\overline{\mathrm{R}}^{2}$ & 0.284 & 0.284 & 0.195 & 0.185 \\
\hline $\mathrm{N}$ & \multicolumn{2}{|c|}{508} & \multicolumn{2}{|c|}{336} \\
\hline
\end{tabular}
a) Absolute t-values in parentheses.
b) $\mathrm{Ln}$ (use +1 ) as continuous variable
c) Dummy variable 
Table 9 Estimation results interacting wages and starting rates of tobacco and alcohol, males age $26-55$ years $(N=508)^{\text {a) }}$

(1)

(2)

\begin{tabular}{|c|c|c|c|c|}
\hline $\begin{array}{l}\text { Starting rates } \\
\text { Education }\end{array}$ & Tobacco & Alcohol & Tobacco & Alcohol \\
\hline Primary & $-0.38(0.7)$ & $-0.15(0.4)$ & $-0.37(0.7)$ & $-0.15(0.4)$ \\
\hline Secondary & $-0.60(1.1)$ & $-0.24(0.6)$ & $-0.60(1.1)$ & $-0.24(0.6)$ \\
\hline $\begin{array}{l}\text { Higher } \\
\text { Religion }\end{array}$ & $-0.71(1.3)$ & $-0.07(0.2)$ & $-0.71(1.3)$ & $-0.07(0.2)$ \\
\hline Catholic & $-0.00(0.0)$ & $-0.25(1.7)$ & $-0.00(0.0)$ & $-0.25(1.7)$ \\
\hline $\begin{array}{l}\text { Protestant } \\
\text { M ass points }\end{array}$ & $-0.07(0.4)$ & $-0.14(0.8)$ & $-0.07(0.4)$ & $-0.14(0.8)$ \\
\hline $\begin{array}{l}v^{a} \\
v^{b} i v^{a} \\
\text { Wages }\end{array}$ & $\begin{array}{c}-3.24(5.3) \\
\text { i } 1\end{array}$ & $\begin{array}{l}-3.03(6.8) \\
-1.17(2.5)\end{array}$ & $\begin{array}{c}-3.23(5.2) \\
\text { i } 1\end{array}$ & $\begin{array}{l}-3.03(6.7) \\
-1.02(2.5)\end{array}$ \\
\hline $\begin{array}{l}\text { Age } \\
\text { Education }\end{array}$ & \multicolumn{2}{|c|}{$0.014(7.8)$} & \multicolumn{2}{|c|}{$0.014(8.2)$} \\
\hline Primary & \multicolumn{2}{|c|}{$0.02(0.3)$} & \multicolumn{2}{|c|}{$0.02(0.2)$} \\
\hline Secondary & \multicolumn{2}{|c|}{$0.14(1.9)$} & \multicolumn{2}{|c|}{0.14 (1.9) } \\
\hline Higher & & \multicolumn{2}{|c|}{$0.36(4.9)$} \\
\hline Tobacco no./ dayb) & & & \multirow{2}{*}{\multicolumn{2}{|c|}{$-0.090(31)$}} \\
\hline Tobacco use, $0^{c)}$ & \multicolumn{2}{|c|}{$-0.033(3.2)$} & & \\
\hline Alcohol no./ dayb) & \multicolumn{2}{|c|}{0.017 (1.8) } & \multicolumn{2}{|c|}{-} \\
\hline $\begin{array}{l}\text { A lcohol use, } \\
\text { M ass points }\end{array}$ & & \multicolumn{2}{|c|}{$0.098(1.7)$} \\
\hline $\begin{array}{l}\begin{array}{l}0 \\
\circ \\
\circ \mathrm{x} \\
0 \\
\mathrm{H} \text { eterogeneity }\end{array}\end{array}$ & \multicolumn{2}{|c|}{$\begin{array}{l}2.69(25.7) \\
-0.19(2.4)\end{array}$} & \multicolumn{2}{|c|}{$\begin{array}{l}2.65(22.8) \\
-0.20(2.4)\end{array}$} \\
\hline (® & \multicolumn{2}{|c|}{$2.25(4.5)$} & \multicolumn{2}{|c|}{$2.10(4.4)$} \\
\hline $\begin{array}{l}\text { ¡ Loglikelihood } \\
\text { i Logl: }\left(\begin{array}{c}\circ x \\
0\end{array}=0\right)\end{array}$ & \multicolumn{2}{|c|}{$\begin{array}{l}2518.50 \\
2521.78\end{array}$} & \multicolumn{2}{|c|}{2517.73} \\
\hline
\end{tabular}

a) A bsolute t-values in parentheses. To save space the coed cients for age dependence in the starting rates are not reported. These coel cients are almost the same as the ones reported in Table 5.

b) $\mathrm{Ln}($ use +1$)$ as continuous variable

c) Dummy variable 
Figure 1a Starting rates for smoking

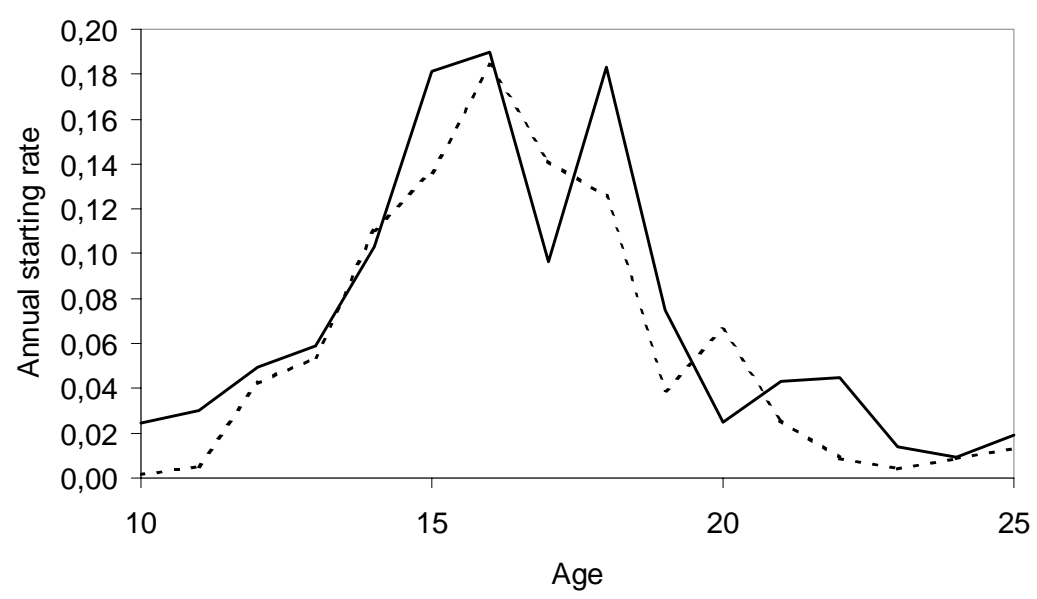

- Males ... Females

Figure $1 \mathrm{~b}$ Starting rates for alcohol

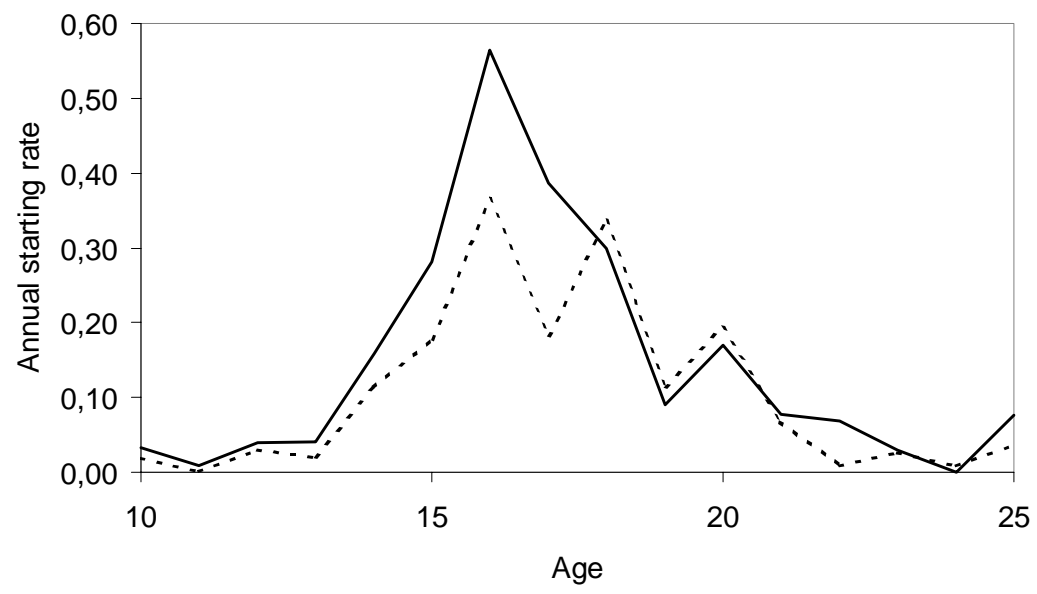

-Males $\cdots$ Females 


\section{IZA Discussion Papers}

M. Galeotti

L. J. Maccini

F. Schiantarelli

459

M. Biewen

460

B. R. Chiswick

Y. Liang Lee

P. W. Miller

M. Gurgand

D. N. Margolis

462

B. R. Chiswick

Y. Liang Lee

P. W. Miller

463

J. Ermisch

M. Francesconi

J. E. Askildsen

E. Bratberg

$\varnothing$. A. Nilsen

A. Venturini

C. Villosio

J. Wagner

R. Lalive

J. C. van Ours

J. Zweimüller
A. Cigno
F. C. Rosati
L. Guarcello

$$
\begin{aligned}
& \text { B. R. Chiswick } \\
& \text { Y. Liang Lee } \\
& \text { P. W. Miller }
\end{aligned}
$$

J. Zweimüller

J. C. van Ours
Title

Area

Date

Inventories, Employment and Hours

5

03/02

The Covariance Structure of East and West

3

03/02

German Incomes and its Implications for the

Persistence of Poverty and Inequality

Family Matter: The Role of the Family in

2

03/02

Immigrants' Destination Language Acquisition

Welfare and Labor Earnings:

3

03/02

An Evaluation of the Financial Gains to Work

The Determinants of the Geographic

$03 / 02$

Concentration among Immigrants: Application to

Australia

Labor Supply Dynamics, Unemployment and

Human Capital Investments

The Hold-Down Problem and the Boundaries of 1 with Endogenous Outside Option

Intergenerational Social Mobility and Assortative Mating in Britain

Unemployment, Labour Force Composition and 1 Sickness Absence: A Panel Data Study

Are Immigrants Competing with Natives in the

04/02 Italian Labour Market? The Employment Effect

04/02

The Impact of Risk Aversion, Role Models, and 1 the Regional Milieu on the Transition from Unemployment to Self-Employment: Empirical Evidence for Germany

The Effect of Benefit Sanctions on the Duration of Unemployment

04/02

Does Globalisation Increase Child Labour?

Immigrants' Language Skills and Visa Category

Structural Change and the Kaldor Facts of

3

04/02 Economic Growth

A pint a day raises a man's pay; but smoking

5

04/02

blows that gain away 